\title{
Estimating Spatial Distribution of Air Temperature from Meteorological Stations Using Atmospheric Model
}

\author{
Sonia Montecinos ${ }^{1,2}$, Luisa Bascuñán-Godoy ${ }^{1}$, Pablo Salinas ${ }^{1}$, Orlando Astudillo ${ }^{1} \&$ David Lopez $^{1}$ \\ ${ }^{1}$ Centro de Estudios Avanzados en Zonas Aridas (CEAZA), La Serena, Chile \\ ${ }^{2}$ Universidad de La Serena, La Serena, Chile \\ Correspondence: Sonia Montecinos, Centro de Estudios Avanzados en Zonas Aridas (CEAZA), La Serena, Chile. \\ E-mail: sonia.montecinos@ceaza.cl
}

\author{
Received: October 18, 2012 Accepted: November 15, $2012 \quad$ Online Published: January 15, 2013 \\ doi:10.5539/jas.v5n2p178 URL: http://dx.doi.org/10.5539/jas.v5n2p178
}

\begin{abstract}
Planning agricultural procedures needs to take into account meteorological conditions. However, because of high associated costs, the density of meteorological stations is often not enough to cover all the cultivated or potentially cultivated areas. In this article we present a methodology to estimate seasonal maximum and minimum mean temperature in cultivated area using data registered in a sole or a few meteorological stations. The procedure is based on mesoscale modeling, which allows meteorological variables to be spatially distributed considering synoptic data and local characteristics.

Simulated daily cycle of temperature was compared with data registered at six meteorological stations located in the cultivated floor of the semiarid Limari Valley $\left(\right.$ Chile, $\left.31^{\circ} \mathrm{S}\right)$. Although in some cases the simulated temperature differs in about $2^{\circ} \mathrm{C}$ with the observed one, a good fit between model results and experimental data was observed. Using the simulated seasonal minimum and maximum mean temperature fields, maps of temperature differences with respect to a reference station were drawn. In order to observe the influence of the orography on the lapse rate around a station, the methodology was applied for two reference stations located in places with different orographic characteristics. Results for winter and summer seasons are shown.

These generated maps can be used by farmers and agricultural planners to obtain information of seasonal minimum and maximum mean temperature from a station in any site of the cultivated area. This technique is a good alternative to obtain meteorological information at low costs, contributing to territorial planning for climate resilient agriculture sustainability.
\end{abstract}

Keywords: mesoscale modeling, air temperature, orography, lapse rate, spatial analysis, agriculture sustainability

\section{Introduction}

Agricultural productivity is severely affected by meteorological parameters such as rainfall, wind speed, solar radiation and air temperature (Hatfield et al., 2011). The break of dormancy, growth rate, fruit quality, and yield production are influenced by changes in environmental conditions (Griffiths, 1994; Steel \& Greer, 2008; Walkovszky, 1998; Salazar-Parra, Aguirreolea, Sánchez-Díaz, Irigoyen, \& Morales, 2010). Because of the close relationship between meteorology and yield production, knowing the meteorological characteristics of a site could help the selection of crops and cultivars best adapted to the area. Therefore farmers often install meteorological stations within their cultivated area. However, it is an expensive undertaking, and currently many cultivable places do not possess a sufficient number of meteorological stations. For this reason, farmers use the nearby station to get meteorological information. However, the validity of this procedure depends on spatial distribution of the meteorological variable in the area (Gomez et al., 2008; Lookingbill \& Urban, 2003), factors for which confidence data are generally not known.

Among the environmental factors, the temperature is one of the most relevant variables in yield production. Maximum and minimum temperatures influence bud formation, shoot growth, time of flowering, fruit formation, ripening, harvest, fruit size and fruit quality (Thuzar, Puteh, Abdullah, Mohd-Lassim, \& Jusoff, 2010; Ferris, Ellis, Wheeler, \& Hadley, 1998; Wheeler, Craufurd, Ellis, Porter, \& Vara-Prasad, 2000).

Spatial distribution of air temperature is influenced by surface characteristics of the area. Soil type and color, land use, soil water content, orography and other local aspects alter the surface energy balance and hence the 
temperature (Kalthoff et al., 2006). Many authors have developed different techniques to spatially distribute temperature records. For example, Gomez et al. (2008) used mathematical interpolation of data registered in meteorological stations improved with climate data, and Lookingbill and Urban (2003) evaluated temperature distribution in a mountain environment from a network of portable temperature micro-loggers and using environmental information such as radiation and slope.

Unlike the methods mentioned above, atmospheric modeling allows the evaluation of temperature taking into account both orographic and synoptic conditions, as well as the physical processes relevant for the temperature behavior (Holton, 1992). Besides, it is possible to calculate values of temperature not only at a single point, but in an extended area. Therefore atmospheric modeling can be a useful tool to estimate temperature at sites without meteorological information.

In this article we report a methodology based on atmospheric modeling, which allows the estimation of temperature over an area from data registered at a meteorological station. This procedure was applied to the cultivated area of the Limari Valley, located in the semi-arid Norte Chico of Chile. We used the KAMM Model (Karlsruhe Atmospheric Mesoscale Model) to evaluate seasonal mean temperature fields over a period of 16 years. This period is large enough to consider interannual variability. To ensure the validity of the model, simulation results were compared with data of meteorological stations located on the cultivated floor of the valley.

We applied the methodology to spatially distribute mean seasonal maximum and minimum mean temperature. Although the study can be performed for all seasons, in this article the results only for the extreme winter and summer were presented. The procedure shown here allows the generation of maps that can be used by farmers to estimate the mean temperature with respect to a reference station (RS). These maps could be used to incorporate climatic factors in crops and territorial planning.

\section{Method}

\subsection{Study Site}

The Limari basin $\left(31^{\circ} \mathrm{S}-31.5^{\circ} \mathrm{S}\right)$ is located in the semi arid Norte Chico of Chile, south of the hyperarid Atacama Desert and about $350 \mathrm{~km}$ north of Santiago de Chile. It extends from the Pacific Ocean eastwards to the Andes Cordillera with elevations until $4500 \mathrm{~m}$. It has an important agricultural activity with a cultivated surface of about 46000 ha. Grapes for table and wine production are the most important cultivars in the valley (Ibacache \& Sierra, 2009).

The mean annual precipitation of the Norte Chico varies from approximately $100 \mathrm{~mm}$ at the coast to $300 \mathrm{~mm}$ at the top of the Andes. It has an important orographic influence (Favier, Falvey, Rabatel, Pradeiro, \& Lopez, 2009) with a Mediterranean rainfall regime and precipitation occurs predominantly in winter months, during the passage of frontal systems from the southern Pacific (Falvey \& Garreaud, 2007). The interannual variability of precipitation is strongly influenced by the El Niño Southern Oscillation, with higher than average amounts during the warm phase (Rutllant \& Fuenzalida, 1991). As a consequence of these characteristics, it was necessary to build artificial lakes to provide water for irrigation, making agricultural productivity less dependent of precipitation.

At the coastal zones the sea breeze can carry humid and cold air from the ocean to the inland zones (Luebert \& Pliscoff, 2006; Kalthoff et al., 2006), which generates a longitudinal climatic gradient, along the East-West oriented valleys such as Limari.

The study site is represented in Figure 1c. It includes the entire cultivated area of the Limari valley, and it covers an area of $70 \times 50 \mathrm{~km}^{2}$ between $71.5^{\circ} \mathrm{W}$ and $70.7^{\circ} \mathrm{W}$ of longitude and $31.0^{\circ} \mathrm{S}$ and $30.9^{\circ} \mathrm{S}$ of latitude. Figure 2 shows the topography (a) and land use classification (b) of the study site. 


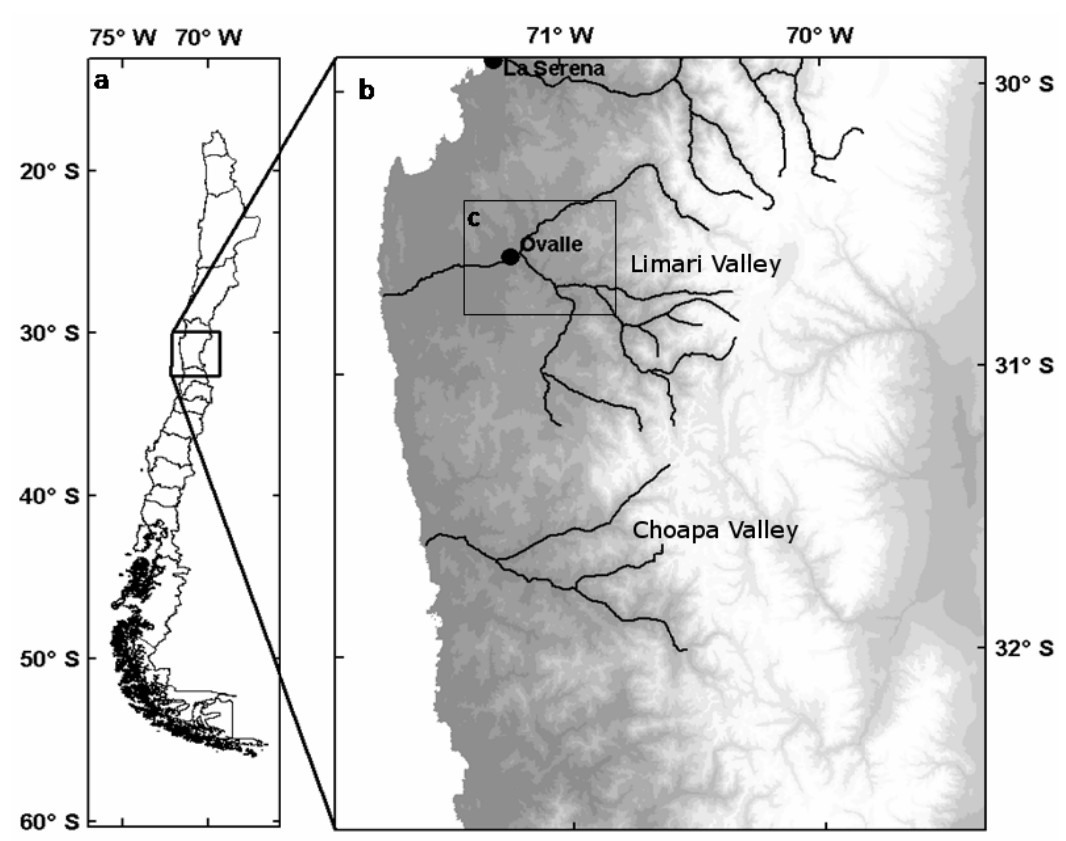

Figure 1. Simulation region. a) shows the location of the simulation region in Chile; b) displays a zoom to the specific simulation region; and c) the study site

a)

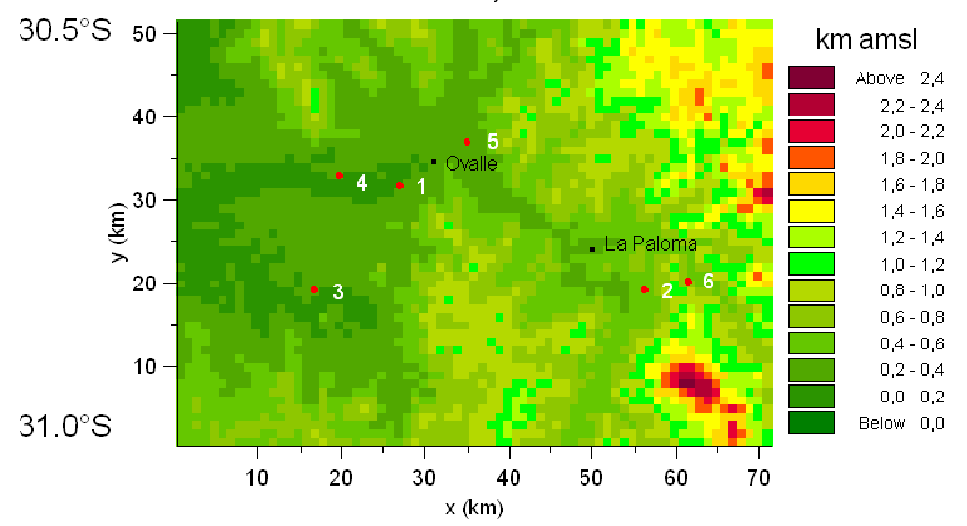

b)

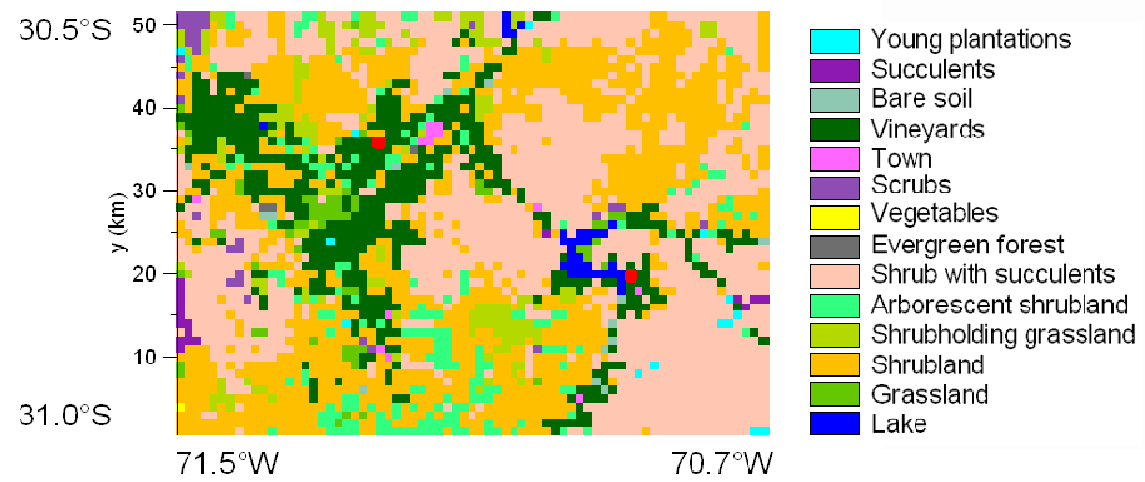

Figure 2. Study area (Limari valley). a) Topography. The six red points represent the position of the meteorological stations used for validation. The stations La Chimba and San Antonio are marked by 1 and 2 respectively. b) Land use. The dark green zones represent the cultivated area of the study site 


\subsection{Mesoscale Modeling}

The numerical simulations were performed with the three-dimensional non-hydrostatic Karlsruhe Atmospheric Mesoscale Model (KAMM; Adrian \& Fiedler, 1991). The model consists of two components, the atmospheric and the soil vegetation module (Schaedler, Kalthoff, \& Fiedler, 1990). It solves the momentum, heat, and humidity equations, transformed onto a coordinate system which follows the terrain. It needs as input data information from the large-scale synoptic weather situation (profiles of temperature, humidity and wind) as well as topography, soil types and land use. More information about the model can be found in Bischoff-Gauß, Kalthoff, and Fiebig-Wittmaack (2006); Montecinos, Boersch-Supan, Favier, Astudillo, and Tracol (2008).

We evaluated the mean meteorological conditions for a period of 16 years, from 1990 to 2006. The methodology was based on cluster analysis (Anderberg, 1973; Ward, 1963), which is a method to identify groups or clusters with common patterns. The variables selected to define similarity were i) zonal wind, ii) meridional wind, both at 500 $\mathrm{hPa}$ pressure level, and iii) vertical potential temperature gradient (Holton, 1992) between $850 \mathrm{hPa}$ and $500 \mathrm{hPa}$. The criteria used for clustering is the Euclidean Distance as distance coefficient (Wilks, 2006) and the Ward's method as grouping algorithm (Ward, 1963). The cluster analysis is commonly used in atmospheric modeling to evaluate averages over long periods of time (Mengelkamp, 1999; Jiménez, González-Rouco, Montávez, García-Bustamante, \& Navarro, 2009; Davisa, Edera, Nychkaa, \& Yanga, 1998).

The mean meteorological conditions were calculated as follow: for each cluster a simulation with the KAMM model was performed. The initial profiles of temperature, humidity and wind needed to initialize the model, were calculated by taking an average over all members of the cluster. The profiles were taken from the National Center for Environmental Prediction/NCAR Reanalysis (Kalnay et al., 1996).

The mean meteorological characteristics were calculated by averaging the cluster simulations, taking into account the specific weight of each one.

\subsection{Simulation Region and Model Setup}

The simulation region is shown in Figure 1b. It is located within the semi-arid zone of the Norte Chico of Chile, south of La Serena city. It covers an area of $256 \times 303 \mathrm{~km}^{2}$ between $72.0^{\circ} \mathrm{W}$ and $70.2^{\circ} \mathrm{W}$ of longitude and $31.8^{\circ} \mathrm{S}$ and $30.2^{\circ} \mathrm{S}$ of latitude. The region includes the transversal Limari and Choapa valleys. The terrain is complex, with heights that vary from the sea level at the Pacific coast to $5500 \mathrm{~m}$ at the Andes Cordillera.

The upper limit of the model was set at $10 \mathrm{~km}$ altitude. The simulation region was divided horizontally into $1 \times 1$ $\mathrm{km}^{2}$ cells and vertically into 40 layers. The land use classification was taken from CONAF and CONAMA (1999). The land use classes were adapted to the KAMM land use classification and some new categories were aggregated, so that 14 classes remain in the model.

The environmental input data were taken from the following sources: initial vertical profiles from National Center for Environmental Prediction/NCAR Reanalysis (Kalnay et al., 1996); earth surface temperature was set $1{ }^{\circ} \mathrm{C}$ colder than the lower air temperature, inferred from experimental data registered at the meteorological station San Carlos $\left(30.06^{\circ} \mathrm{S}, 70.82^{\circ} \mathrm{W}\right)$. The temperature of the Pacific Ocean was taken from satellite data (reference in Reynolds, Rayner, Smith, Stokes, \& Wang, 2002).

\subsection{Spatial Estimation of Air Temperature Based on a Reference Station (RS)}

We used atmospheric model for evaluating the mean fields of minimum and maximum temperature, in winter (June, July and August) and summer (December, January and February), over the study site. In all cases, the mean temperature field $T(x, y)$ was evaluated at $2 \mathrm{~m}$ above ground level, according to the standard height of the temperature sensor in agrometeorological stations.

In order to estimate the temperature from a RS, we evaluated the field of temperature difference $\Delta T(x, y)$ with respect to it over the entire study site. $\Delta T(x, y)$ is defined as $T(x, y)-T_{o}$, with $T(x, y)$ the field of temperature, and $T_{o}$ the simulated temperature at the RS. Both quantities, $T(x, y)$ and $T_{o}$, were simulated results obtained with the KAMM model.

The procedure described above was performed for four cases: minimum and maximum temperature, for winter and summer.

The field of temperature differences was evaluated separately for two RS on the cultivated floor of the valley: La Chimba and San Antonio, two locations that are indicated in Figure 2a by 1 and 2, respectively, and by red points in Figure 2b. These stations are located on different orographic conditions: La Chimba $\left(30.59^{\circ} \mathrm{S}, 71.14^{\circ} \mathrm{W}, 270 \mathrm{~m}\right.$ above mean sea level), on the flat valley floor surrounded by cultivated areas, and San Antonio $\left(30.74^{\circ} \mathrm{S}, 70.93^{\circ} \mathrm{W}\right.$, 
$485 \mathrm{~m}$ above mean sea level), on a hill in the proximity of the Andes Cordillera, and about $1 \mathrm{~km}$ east of a water reservoir (Figure 2). These stations were chosen to test the method on two different and contrasting conditions.

\section{Results}

\subsection{Model Validation}

In order to verify whether the model reproduces the near surface climatic near surface characteristics of the valley system, model results were compared with the observed ones in six meteorological stations located in the study site. Figure 3 displays the mean diurnal cycle of temperature simulated and observed at six meteorological stations. The graphics $3 \mathrm{a}$ to $3 \mathrm{f}$ correspond to the results in winter, and from $3 \mathrm{~g}$ to 31 to summer. The number of the station is indicated at the top of each graphic, and its location is shown in Figure 2a. Although in winter and summer some differences between model results and observations are observed, these differences are at the most $2^{\circ} \mathrm{C}$ (Figure 3). Moreover, the Root Mean Square Error between the simulated and observed temperatures in winter and summer varies between $0.2^{\circ} \mathrm{C}$ and $0.5^{\circ} \mathrm{C}$. So it can be concluded that the model in general satisfactorily describes the temperature behavior in the cultivated area of the Limari Valley, and can potentially be used to obtain secondary information applicable to the agriculture.
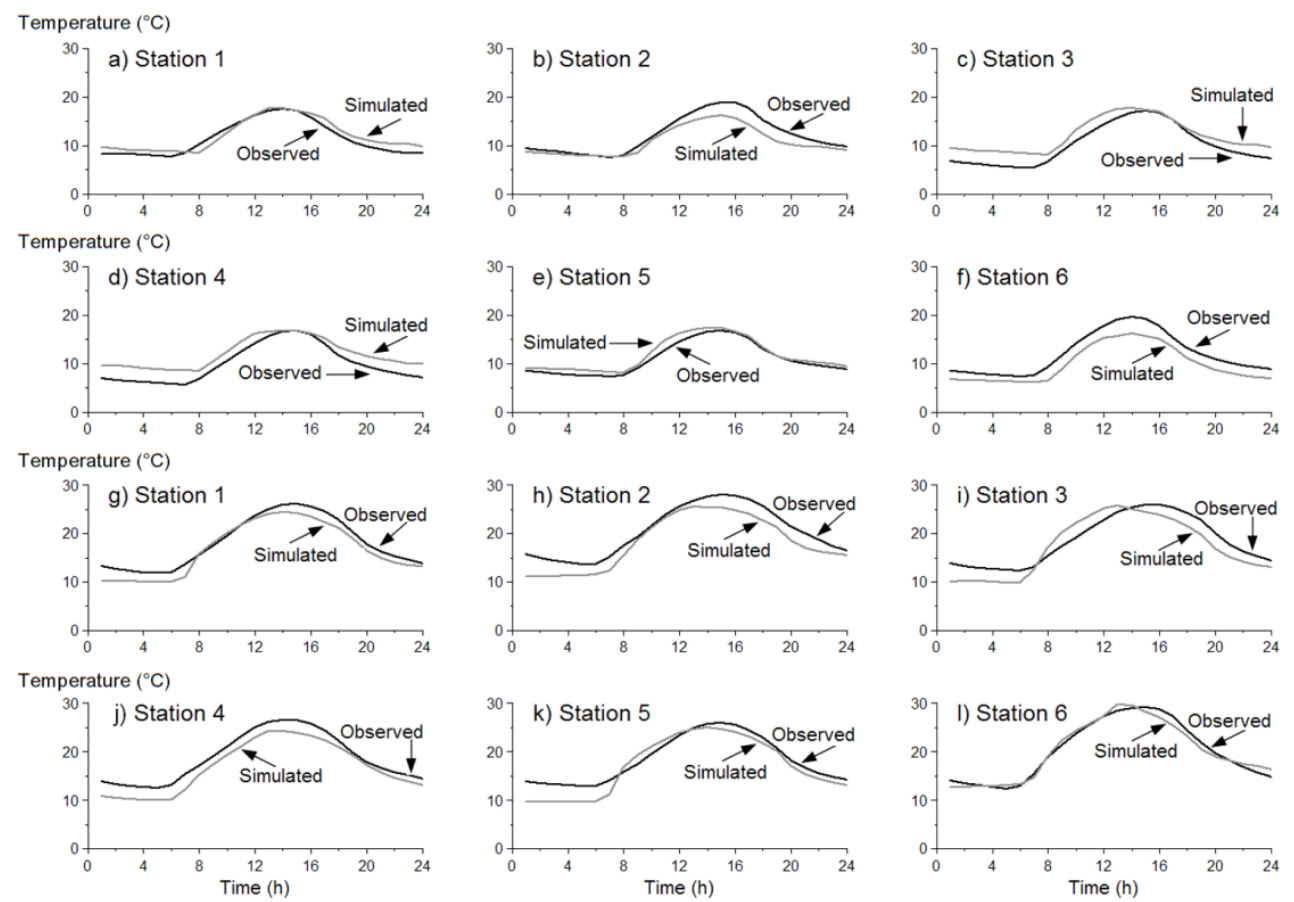

Figure 3. Simulated and observed diurnal cycles of temperature in winter (a), b), c), d), e) and f)) and summer (g), h), i), j), k), 1)) at six meteorological stations in the Limari Valley. At the top of each graphic the number marking the station is indicated, which location is shown in Figure 2

\subsection{Temperature Fields}

Figure 4 shows the simulated mean fields of temperature at 0600 and 1400 local time in winter (Figure 4a, b) and summer (Figure $4 \mathrm{c}, \mathrm{d}$ ), which corresponds approximately to the time when the minimum and maximum temperature are reached. The isolines correspond to the topography. 
a)

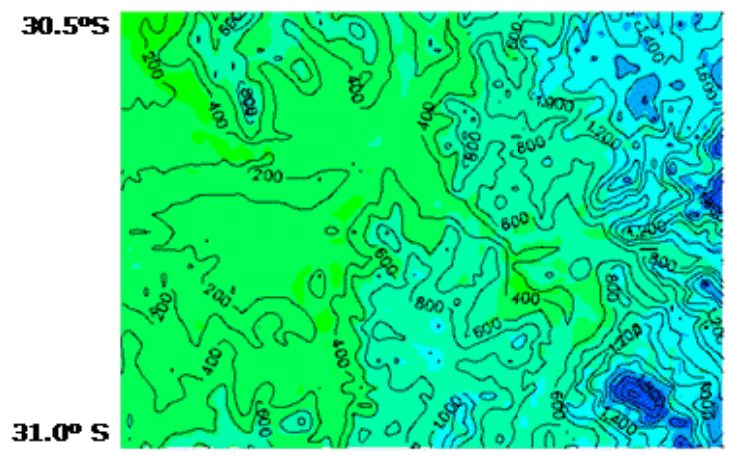

c)

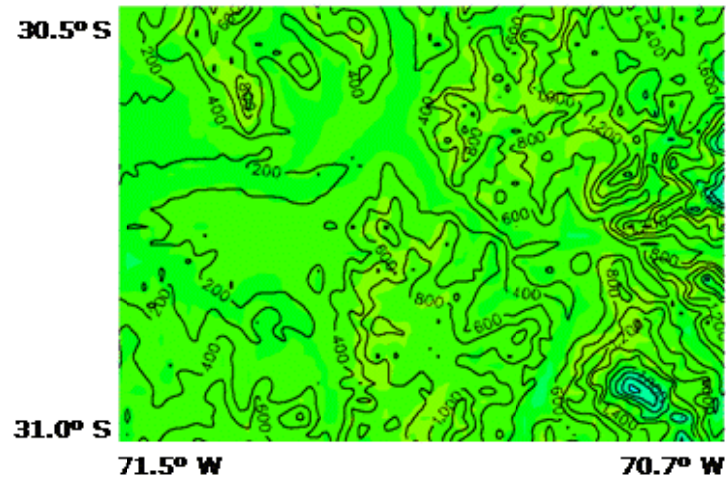

b)

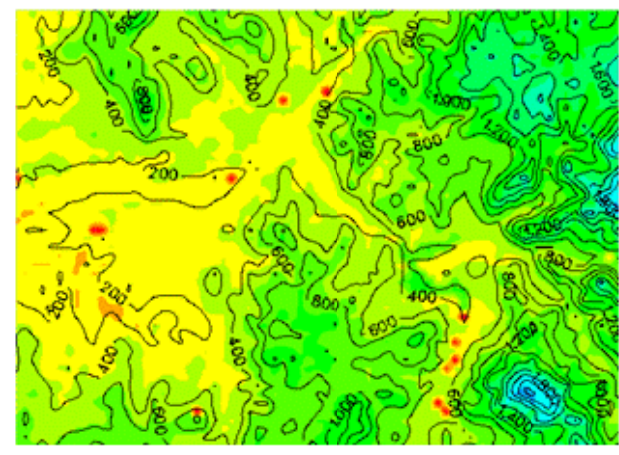

d)

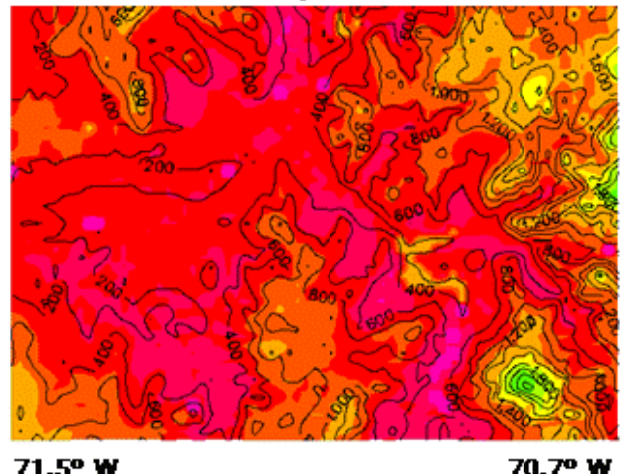

$71.5^{\circ} \mathrm{w}$

Figure 4. Near-surface temperature fields in the study site. a) minimum in winter; b) maximum in winter; c) minimum in summer; d) maximum in summer. The isolines represent the topography (m)

In winter both the minimum (Figure 4a) and maximum (Figure 4b) temperature decreases eastwards achieving in the valley floor values of about $10^{\circ} \mathrm{C}$ and $20^{\circ} \mathrm{C}$, respectively. Comparatively, during the summer the minimum temperature (Figure $4 \mathrm{c}$ ) in the valley floor is of about $11^{\circ} \mathrm{C}$, and presents smaller spatial variations than in winter (Figure 4a). The maximum temperature in summer (Figure $4 \mathrm{~d}$ ) in the cultivated valley floor varies between $25^{\circ} \mathrm{C}$ and $29^{\circ} \mathrm{C}$, and decreases eastwards. A similar behavior can be observed in winter (Figure $4 \mathrm{~b}$ ).

We found that in the valley floor the mean minimum temperature in winter is only around $2^{\circ} \mathrm{C}$ colder than in summer. This effect could be related to the high humidity near the coast (Luebert \& Pliscoff, 2006), which can generate a weakening in surface nocturnal cooling.

The spatial distribution of maximum temperature displays a direct relationship with topography. In winter and summer (Figure $4 \mathrm{~b}$ and $\mathrm{d}$ ) the bottom of the valley displays the highest temperature values, decreasing towards the high mountains at the east of the valley.

\subsection{Spatial Estimation of Temperature from a $R S$}

We evaluated the field of mean differences of minimum and maximum temperature, in winter and summer, with respect to two RS: La Chimba and San Antonio, located on different orographic conditions. The maps for La Chimba and San Antonio are shown in Figures 5 and 6, respectively. Although atmospheric modeling gives continuous values of temperature, as represented in figure 4, for visualization we draw maps that divide the study site into zones with temperature differences in the range of $1^{\circ} \mathrm{C}$ (Figures 5 and 6). The red points indicate the position of the RS. In the individual maps, the brown area depicts the zones warmer than the station, while the green zone the colder ones; the darker the color the larger the absolute temperature difference. In the white area, the absolute temperature differences are higher than $3^{\circ} \mathrm{C}$. We plot absolute temperature differences smaller than $3^{\circ} \mathrm{C}$, because in all cases, all of the cultivated area presents differences in this range. 
a)

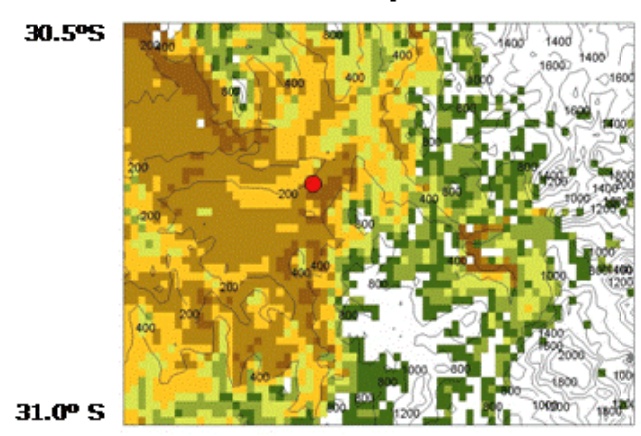

c)

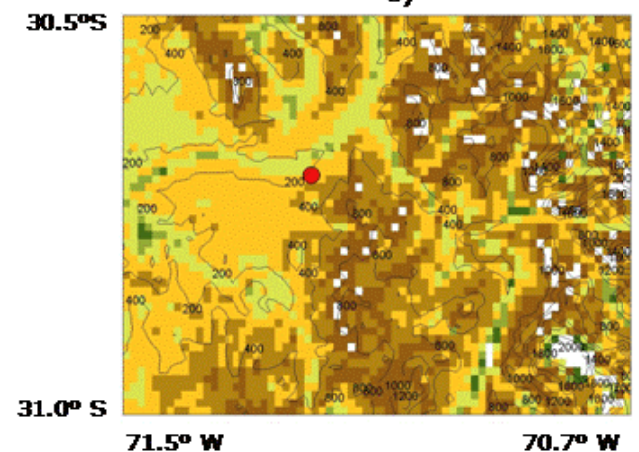

b)

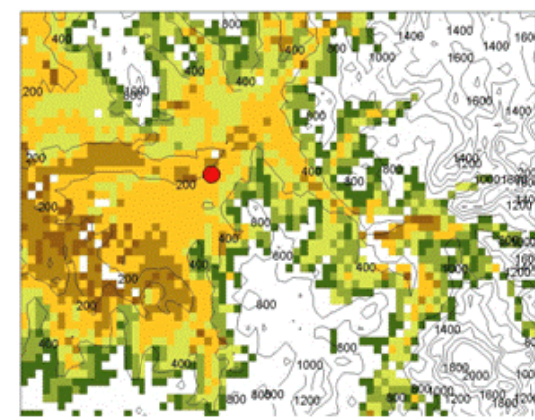

d)

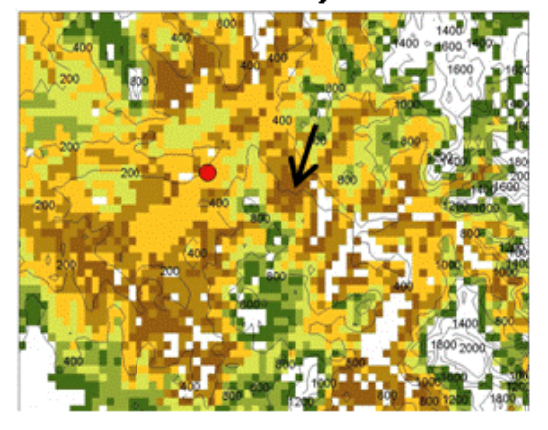

$70.7^{\circ} \mathrm{w}$

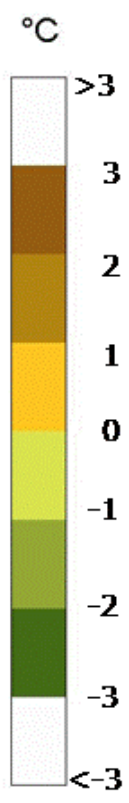

$71.5^{\circ} \mathrm{w}$

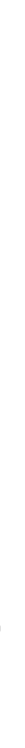

Figure 5. Temperature differences with respect to La Chimba station (red circle). a) minimum in winter; b) maximum in winter; c) minimum in summer; d) maximum in summer. The isolines represent the topography (m)

a)

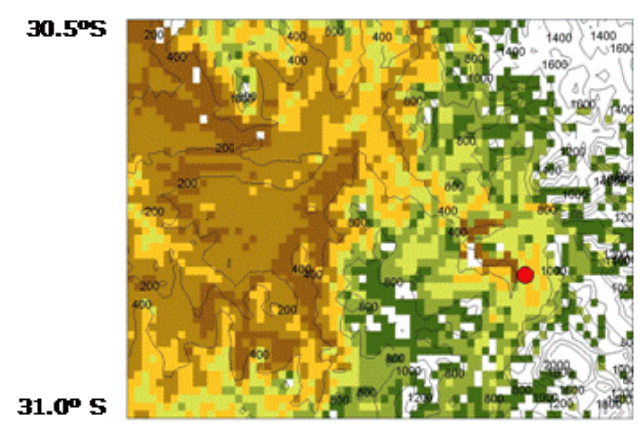

c)

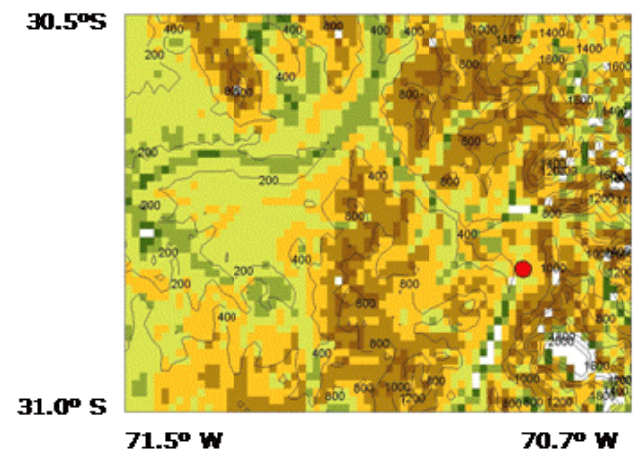

b)

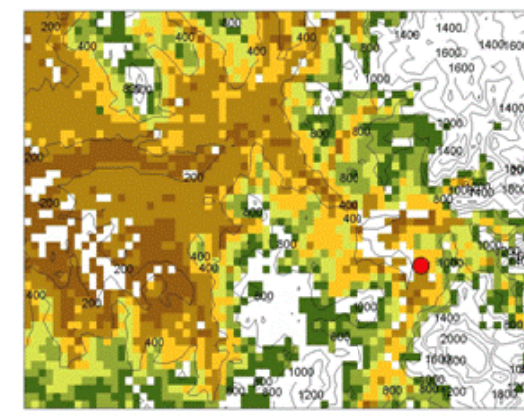

d)

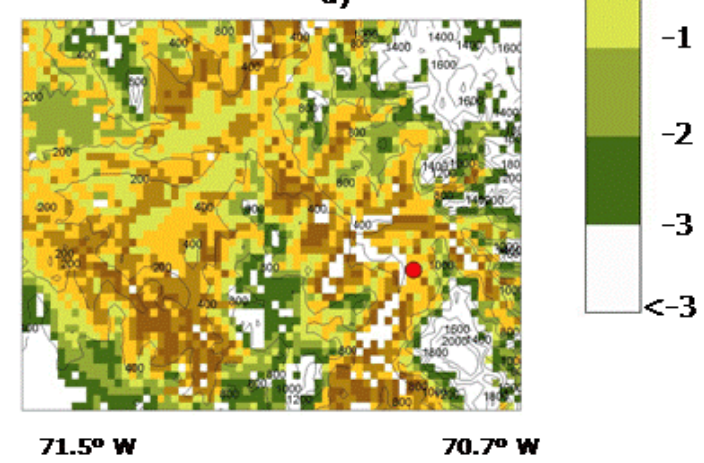

Figure 6. Temperature differences with respect to San Antonio station (red circle). a) minimum in winter; b) maximum in winter; c) minimum in summer; d) maximum in summer. The isolines represent the topography (m) 
In the case of La Chimba station (Figure 5), in all events a smooth variation of temperature around the station was observed. In winter and summer, the minimum temperature varies less than the maximum one. In the case of maximum temperature, the points outside the range of $3^{\circ} \mathrm{C}$ observed in winter (Figure 5b) and summer (Figure 5d), fall outside the cultivated zone.

We note that the variation of temperature around San Antonio is higher than in La Chimba, which could be attributed to the orographic characteristics of the location of San Antonio station and differences in soil use, all of which alters surface energy balance, thereby inducing differential heating rates of the ground (Kalthoff et al., 2006).

\section{Discussion}

In this article a methodology based on atmospheric modeling to estimate the mean temperature in cultivated areas from data registered in one meteorological station was proposed. We used the KAMM model to evaluate mean temperature fields, in winter and summer, and the results were compared with data of six meteorological stations. A good fit between data and model results was found.

Model results were used to draw maps of minimum and maximum temperature differences between the study site and the temperature at a RS. Both, the temperature at the study site and the one at the RS, were simulated results. This procedure was performed for winter and summer, using two RS, located at places with different orographic conditions.

The resulting maps can be used by farmers to estimate the mean minimum and maximum temperature in any place of the cultivated area. For example, if a farmer wants to know maximum temperature in summer based on data records in La Chimba station, he/she should use the map shown in Figure 5d. If the site is the one indicated by the arrowhead (Figure 5d) the farmer can estimate the maximum temperature adding $3^{\circ} \mathrm{C}$ to the maximum temperature recorded in La Chimba. We remark that when the temperature is operating at its extremes in winter or summer months during crop season in the agricultural field, these maps may be used cautiously.

This technique can be applied for any variable, such as mean temperature, evapotranspiration, wind velocity and humidity. The methodology shown in this article can be reproduced in any site, using the KAMM model or other mesoscale model, such as Weather Research and Forecasting WRF model (http://wrf-model.org).

It is important to mention that the spatial resolution used in mesoscale modeling limits the validity of the results. If the study area has a very complex topography, it could be necessary to increase the spatial resolution of the model simulations.

Using atmospheric mesoscale models would enable the reduction of costs associated with maintenance and/or installation of meteorological stations, even in areas with complex topography. Further, it allows to know temperature using a RS, not only in the cultivated area but beyond, enables the assessment of new cultivable ones.

\section{Acknowledgements}

This work was supported by CONICYT, Project FONDEF D05I10038 and the International Exchange Project BMBF - CONICYT 066-2007. The authors thank SCC (Steinbuch Centre for Computing, Karlsruhe Institut für Technologie (KIT), Germany) for the supply of computing time on NEC SX8 in the context of CampusGrid Project. We thank I. Bischoff-Gauss and N. Kalthoff for useful discussion.

\section{References}

Adrian, G., \& Fiedler, F. (1991). Simulation of unstationary wind and temperature fields over complex terrain and comparison with observations. Contributions to Atmospheric Physics, 64, 27-48.

Anderberg, M. R. (1973). Cluster Analysis for Applications. New York: Academic Press.

Bischoff-Gauß, I., Kalthoff, N., \& Fiebig-Wittmaack, M. (2006). The influence of a storage lake in the arid Elqui valley in Chile on local climate. Theoretical and Applied Climatology, 85, 227-241.

Buffo, E., Battisti, A., Stastny, M., \& Larsson, S. (2007). Temperature as a predictor of survival of the pine processionary moth in the Italian Alps. Agricultural and Forest Entomology, 9, 65-72. http://dx.doi.org/10.1111/j.1461-9563.2006.00321.x.

Conaf, C. (1999). BIRF, Universidad Austral de Chile, Pontificia Universidad Católica de Chile, Universidad Católica de Temuco. Catastro y evaluación de los recursos vegetacionales nativos de Chile. Informe nacional con variables ambientales. Santiago, Chile. 
Davisa, J. M., Edera, B. K., Nychkaa, D., \& Yanga, Q. (1998). Modeling the effects of meteorology on ozone in Houston using cluster analysis and generalized additive models, Atmospheric Environment, 32, 2505-2520. http://dx.doi.org/10.1016/S1352-2310(98)00008-9.

Falvey, M., \& Garreaud, R. (2007). Wintertime precipitation episodes in Central Chile: associated meteorological conditions and orographic influences. Journal of Hydrometeorology, 8, 171-193.

Favier, V., Falvey, M., Rabatel, A., Pradeiro, E., \& Lopez, D. (2009). Interpreting discrepancies between discharge and precipitation in high-altitude area of Chile's Norte Chico region (26-32 $\left.{ }^{\circ} \mathrm{S}\right)$. Water Resources Research, 45, 1-20. http://dx.doi.org/10.1029/2008WR006802.

Ferris, R., Ellis, R. H., Wheeler, T. R., \& Hadley, P. (1998). Effect of high temperature stress at anthesis on grain yield and biomass of field grown crops of wheat. Annals of Botany, 82, 631-639.

Gomez, J. D., Etchevers, J. D., Monterroso, A. I., Gay, C., Campo, J., \& Martinez, M. (2008). Spatial estimation of mean temperature and precipitation in areas of scarce meteorological information. Atmosfera, 21, 35-56.

Griffiths, J. F. (1994). Handbook of agricultural meteorology. New York: Oxford University Press.

Hatfield, J. L., Boote, K. J., Kimball, B. A., Ziska, L. H., Izaurralde, R. C., Ort, D., Thomson, A. M., \& Wolfe, D. (2011). Climate Impacts on Agriculture: Implications for Crop Production. Agronomy Journal, 103, $351-370$.

Holton, J. R. (1992). An Introduction to Dynamic Meteorology. San Diego: Academic Press.

Ibacache, G., \& Sierra, C. (2009). Influence of rootstocks on nitrogen, phosphorus and potassium content in petioles of four table grape varieties. Chilean Journal of Agricultural Research, 69(4), 503-508.

Jiménez, P. A., González-Rouco, J. F., Montávez, J. P., García-Bustamante, E., \& Navarro, J. (2009). Climatology of wind patterns in the northeast of the Iberian Peninsula. International Journal of Climatology, 29, 501-525. http://dx.doi.org/10.1002/joc.1705.

Kalnay, E., Kanamitsu, M., Kistler, R., Collins, W., Deaven, D., Gandin, L., ... Reynolds, R. (1996). The NCEP/NCAR 40-Year Reanalysis Project. Bulletin of the American Meteorological Society, 77, 437-471.

Kalthoff, N., Fiebig-Wittmaack, M., Meißner, C., Kohler, M., Uriarte, M., Bischoff-Gauß, I., \& Gonzales, E. (2006). The energy balance, evapotranspiration and nocturnal dew deposition of an arid valley in the Andes. Journal of Arid Environment, 65, 420-443.

Lookingbill, T. R., \& Urban, D. L. (2003). Spatial estimation of air temperature differences for landscape-scale studies in montane environments. Agricultural and Forest Meteorolog, 114, 141-151.

Luebert, F., \& Pliscoff, P. (2006). Sinopsis Bioclimatica y Vegetacional de Chile. Editorial Universitaria, Universidad de Chile, Santiago.

Mengelkamp, H. T. (1999). Wind Climate Simulation over Complex Terrain and Wind Turbine Energy Output Estimation. Theoretical and Applied Climatology, 63, 129-139.

Montecinos. S., Boersch-Supan, W., Favier, V., Astudillo, O., \& Tracol, Y. (2008). Impacts of Agricultural Activities on the Regional Climate in an Arid Zone in Chile. Die Erde, 139, 77-95.

Reynolds, R. W., Rayner, N. A., Smith, T. M., Stokes, D. C., \& Wang, W. (2002). An improved In Situ Satellite SST Analysis for Climate. Journal of Climate, 15, 1609-1625. http://dx.doi.org/10.1175/1520-0442(2002)015<1609:AIISAS>2.0.CO;2.

Rutllant. J., \& Fuenzalida, H. (1991). Synoptic aspects of central rainfall variability associated with the Southern Oscillation. International Journal of Climatology, 11, 63-76. http://dx.doi.org/10.1002/joc.3370110105.

Salazar-Parra, C., Aguirreolea, J., Sánchez-Díaz, M., Irigoyen, J. J., \& Morales, F. (2010). Effects of climate change scenarios on Tempranillo grapevine (Vitis vinifera L.) ripening: response to a combination of elevated CO2 and temperature, and moderate drought. Plant and Soil, 337(1), 179-191.

Schaedler, G., Kalthoff, N., \& Fiedler, F. (1990). Validation of a model for heat, mass and momentum exchange over vegetated surfaces using LOTREX-10E=HIBE88 data. Contributions to Atmospheric Physics, 63, $85-100$.

Steel, C. C., \& Greer, D. H. (2008). Effect of climate on vine and bunch characteristics: bunch rot disease susceptibility. Acta Horticulturae, 785, 253-262. 
Thuzar, M., Puteh, A. B., Abdullah, N. A. P., Mohd-Lassim, M. B., \& Jusoff, K. (2010). The Effects of Temperature Stress on the Quality and Yield of Soya Bean [(Glycine max L.) Merrill.]. The Journal of Agricultural Science, 2(1), 172-179.

Walkovszky, A. (1998). Changes in phenology of the locust tree (Robinia pseudoacacia L.) in Hungary. The International Journal of Biometeorology, 41, 155-160.

Ward, J. H. (1963). Hierarchical grouping to optimize an objective function. Journal of the American Statistical Association, 58, 236-244.

Wheeler, T. R., Craufurd, P. Q., Ellis, R. H., Porter, J. R., \& Vara-Prasad, P. V. (2000). Temperature variability and the yield of annual crops. Agriculture, Ecosystems \& Environment, 82, 159-167. http://dx.doi.org/10.1016/j.bbr.2011.03.031. 